\title{
Equilibrium and kinetic approach of bioadsorbed metanil yellow from aqueous solution onto cross- linked magnetic chitosan nanoparticles
}

\author{
$\underline{\text { Tuba Tarhan }}^{1,2,}$, Bilsen Tural ${ }^{2}$, Servet Tural ${ }^{2}$
}

\begin{abstract}
Glutaraldehyde cross-linked magnetic chitosan nanoparticles (GMCNs) were prepared through crosslinking modification of magnetic chitosan nanoparticles (MCNs) using glutaraldehyde as crosslinker that exhibited excellent Metanil Yellow (MY) adsorption performance. The characterization of synthesized GMCNs was performed by Fourier transform infrared spectroscopy (FTIR), transmission electronmicroscopy (TEM), scanning electron microscopy (SEM), dynamic light scattering (DLS), and vibrating sample magnetometry (VSM) analyses. Adsorption characteristics of MY aqueous solutions on to GMCNs
\end{abstract}

Keywords: Biosorption, Crosslinked-Magnetic Chitosan, Metanil Yellow, Regeneration

\section{Introduction}

Metanil yellow is highly water-soluble azo dye which is widely used in dyestuff, textiles, leather, paper, polishes, food, cosmetic and wax industries (1). But it is often released in effluents during processing and transforming and causing a lot of healthy and environmental problems $(2,3)$.Hence, it is a major pullutant and various workers have made attempts to remove Metanil Yellow from wastewater (4).

Chitosan is acknowledged as an easily-available and inexpensive sorbent. Owing to the fact that it possesses amine and hydroxyl functional groups, it is characterized by a high adsorption effectiveness of metal ions (5) and dyes from aqueous solutions (6). A drawback of chitosan is its solubility in acidic solutions. At $\mathrm{pH}<5.5$, it is being dissolved and loses its capacity for sorbates binding. A solution to this problem may be its cross-linking. The crosslinked chitosan maintains constant reactivity in a wide $\mathrm{pH}$ range and is characterized by high mechanical resistance (7). The cross-linking may also affect the improvement of its regeneration properties (8).

Tuba Tarhan/Vocational High School of Health Services

Mardin Artuklu University, 47100, Mardin

Turkey

Bilsen Tural/Department of Chemistry, Faculty of Education

Dicle University, 21280, Diyarbakir

Turkey have been studied and results indicated that the adsorption capacities were affected by initial $\mathrm{pH}$ values, initial dye concentrations and contact time. MY adsorption followed with the pseudo-second-order reaction, and equilibrium experiments were well fitted the Langmuir isotherm model. Maximum adsorption capacities of MY displayed at $\mathrm{pH} 4.0$ and at $30{ }^{\circ} \mathrm{C}$, being up to $625 \mathrm{mg}$ per g GMCNs. Furthermore, it was found that the GMCNs can be regenerated and reused through dye desorption in alkaline solution.

Servet Tural/ Department of Chemistry, Faculty of Education Dicle University, 21280, Diyarbakir Turkey

In the this study, glutaraldehyde cross-linked magnetic chitosan nanoparticles (GMCNs) were prepared through crosslinking modification of magnetic chitosan nanoparticles (MCNs) using glutaraldehyde as crosslinker that exhibited excellent Metanil Yellow adsorption performance. In addition, the adsorption characteristics of Metanil Yellow from aqueous solutions on GMCNs were investigated. Furthermore, the influence factors such as $\mathrm{pH}$, contact time, adsorbent dose and dye concentrations to adsorption were studied; the equilibrium isotherms parameters and regeneration were determined and discussed.

The MY adsorption capacity of the GMCNs was depend on $\mathrm{pH}$ and the initial dye concentration. High adsorption capacities were obtained in the $\mathrm{pH}$ range of 3.0-4.0 to remove the anionic dye. The adsorption capacity increased with increase in initial dye concentration and with decrease in $\mathrm{pH}$.

The maximum monolayer adsorption capacity is $625 \mathrm{mg} \mathrm{g}^{-1}$ for dye $\mathrm{MY}$ at $\mathrm{pH} 4$ and at $30{ }^{\circ} \mathrm{C}$. The Langmuir isotherm model agrees with experimental data better than the Freundlich. In addition, GMCNs can be desorbed efficiently using alkaline solution because adsorption process was spontaneous and exothermic. Desorption studies as a function of $\mathrm{pH}$ were conducted to analyze the possibility of 
reusing the adsorbent for further adsorption and to make the process more economical. Thus, the adsorbent was used for three adsorption cycles for dye removal. After adsorption experiments the dye loaded GMCNs were washed with distilled water to remove any non-adsorbed dye and then were incubated with $\mathrm{NH}_{4} \mathrm{OH} / \mathrm{NH}_{4} \mathrm{Cl}$ buffer. The technique used in this study offered a convenient and efficient method for the preparation of the GMCNs, which facilitated a more efficient and economic adsorption of dye from aqueous solution (adsorbed 65\% of MY after three repeats) and avoided secondary pollution of adsorbents to water environment.

\section{References}

[1] A. Mittal, V.K. Gupta, A. Malviya and J. Mittal, "Process development for the batch and bulk removal and recovery of a hazardous, water-soluble azo dye (Metanil Yellow) by adsorption over waste materials (Bottom Ash and De-Oiled Soya)", J. Hazard. Mater., 151(2008)821-832.

[2] O. Anjaneya, S.Y. Souche, M. Santoshkumar and T.B. Karegoudar, "Decolorization of sulfonated azo dye Metanil Yellow by newly isolated bacterial strains: Bacillus sp. strain AK1 and Lysinibacillus sp. strain AK2", J. Hazard. Mater., 190(2011)351-358.

[3] G. Xiaoyao, W. Qin, D. Bin, Z. Yakun, X. Xiaodong, Y. Liangguo and Y. Haiqin,"Removal of Metanil Yellow from water environment by amino functionalized graphenes (NH2-G) - Influence of surface chemistry of NH2-G", Appl. Surf. Sci., 284(2013)862-869.

[4] T. Robinson, G. McMullan, R. Marchant and P. Nigam, "Remediation of dyes in textile effluent: a critical review on current treatment technologies with a proposed alternative", Bioresour. Technol., 77(2001)247-255.

[5] W.S. Wan Ngah, L.C. Teong and M. Hanafiah, "Adsorption of dyes and heavy metal ions by chitosan composites: A review", Carbohydr. Polym., 83(2011)1446-1456.

[6] M.C. Shih, "Kinetics of the batch adsorption of methylene blue from aqueous solutions onto rice husk: effect of acid-modifi ed process and dye concentration", Desalin. Water Treat., 37 (2012) 200214

[7] W. Ngah, S. Ab Ghani and A. Kamari, "Adsorption behaviour of $\mathrm{Fe}$ (II) and Fe (III) ions in aqueous solution on chitosan and crosslinked chitosan beads", Bioresour. Technol., 96(2005)443-450.

[8] A. Kamari, W.S.W. Ngah, M.Y. Chong and M.L. Cheah, "Sorption of acid dyes onto GLA and H2SO4 cross-linked chitosan beads", Desalination, 249(2009)1180-1189. 